\title{
Persulfate treatment as a method of modifying carbon electrode material for aqueous electrochemical capacitors
}

\author{
Kacper Kopczyński ${ }^{1}$ • Daria Pęziak-Kowalska ${ }^{1}$ - Katarzyna Lota ${ }^{2} \cdot$ Tomasz Buchwald $^{3}$. \\ Anna Parus ${ }^{4} \cdot$ Grzegorz Lota $^{1}$
}

Received: 16 August 2016 / Revised: 22 October 2016 / Accepted: 26 October 2016 / Published online: 12 November 2016

(C) The Author(s) 2016. This article is published with open access at Springerlink.com

\begin{abstract}
The activated carbon was modified by the wet method with a solution of ammonium persulfate at room temperature with different times. Kinetics studies showed that the modification took place mostly during the first $60 \mathrm{~min}$ of the process. The physicochemical properties of the obtained carbon were evaluated by thermogravimetric studies, Raman and FTIR spectroscopy, elementary and BET analyses. Furthermore, the fabricated material was applied in symmetric capacitors operated on the three aqueous electrolytes (1 M $\mathrm{H}_{2} \mathrm{SO}_{4}, 6 \mathrm{M} \mathrm{KOH}$ and $1 \mathrm{M} \mathrm{Na}_{2} \mathrm{SO}_{4}$ ). Mild conditions of the modification process are optimal to obtain electroactive groups on the carbon surface, which make this material useful in a supercapacitor application. In our studies, we noticed that this type of functional groups mainly appears on the surface of the activated carbon, in the first oxidation stage. With prolonged oxidation, they may transform into undesirable groups. The results show that this kind of modification improves the capacity of all the tested supercapacitors. It was connected mainly with an increase of the carbon material's wettability and in the case of capacitor operated in acid and base electrolytes due to a redox reaction of oxygen functional groups.
\end{abstract}

Grzegorz Lota

grzegorz.lota@put.poznan.pl

1 Institute of Chemistry and Technical Electrochemistry, Poznan University of Technology, Berdychowo 4, 60-965 Poznan, Poland

2 Institute of Non-Ferrous Metals Division in Poznan Central Laboratory of Batteries and Cells, Forteczna 12, 61-362 Poznan, Poland

3 Institute of Material Research and Quantum Engineering, Poznan University of Technology, Piotrowo 3, 60-965 Poznan, Poland

4 Institute of Chemical Technology and Engineering, Poznan University of Technology, Berdychowo 4, 60-965 Poznan, Poland
Keywords Activated carbon - Supercapacitor · Ammonium persulfate $\cdot$ Surface modification $\cdot$ Oxygen functional groups

\section{Introduction}

The activated carbons are considered as highly eco-friendly and cheap materials. Because of this, they are applied in the various environmental protection processes (for example, capacitive desolation, adsorption methods of removal pollution) and are wide spread in the industry (catalyst support etc.) [1-5]. Carbon materials have gained attention in energy storage devices. In the light of nowadays development, a gradual increase of the used electronic equipment is observed, which request the small device able to store enormous energy. The electrochemical double layer capacitors are one of the intensively studied solutions to this problem [6-8].

The capacitors are composed of two electrodes, separator and electrolyte. The electric charge can be stored in the electrode material of capacitors by two ways: electrostatically in the double layer and in faradaic reactions of functional groups on the surface of the electrode material. The electrochemical performance of the supercapacitor in a large degree depends on the physical and chemical properties of the electrode material. The activated carbon is the most frequently used active material for supercapacitors. The porosity and developed surface have a significant impact on its performance. The complex porous structure of activated carbons, with a wide range of pore sizes and their hydrophilic or hydrophobic character, play a crucial role in activated carbons applied in supercapacitors working in aqueous solutions $[9,10]$. Moreover, the occurrence of functional groups on the surface of the electrode material and their character has high impact on the whole device. It can be found that the oxygen and nitrogen functional groups are the most commonly studied 
in the context of the electrochemical performance of materials $[8,11-16]$.

To improve the capacitance properties of the carbon materials, various modification processes are used. Chemical methods enable to insert heteroatoms in the form of functional groups into the material structure and modify the surface area in various extents. They can be divided into dry and wet methods. It the case of an electrochemical application, the activated carbon modified by dry methods is most frequently used. Mostly $\mathrm{KOH}, \mathrm{NaOH}, \mathrm{H}_{3} \mathrm{PO}_{4}$ and $\mathrm{ZnCl}_{2}$ are used with high temperature and inert atmosphere, in order to develop the surface area of the carbon material [7, 17-19]. However, the application of steam, oxygen or plasma treatment can also incorporate the heteroatoms into the structure of carbon, which also has an influence on the electrochemical properties of the active material $[2,20,21]$. On the other hand, the wet methods are based on treatment of the carbon material by the strong modifier solution, for example, $\mathrm{HNO}_{3}, \mathrm{H}_{3} \mathrm{PO}_{4}, \mathrm{H}_{2} \mathrm{O}_{2}$ and persulfate salt solution. The carbons modified by wet methods are more frequently used as adsorbents in environmental applications $[1,2,17,22,23]$. One of the modifying methods is oxidation with the ammonium persulfate solution $[12,24,25]$. In the literature, it is noted that the oxidation conditions, including concentration, time and temperature, have a significant influence on the physicochemical properties of the obtained modified, activated carbon [11]. This modification mainly introduces the oxygen-containing functional groups into the surface of the carbon without extreme changes in the surface area and pore structure, in opposite to the $\mathrm{HNO}_{3}$ modification [23] which is unprofitable in a supercapacitor application. It was determined that the described modification processes are longer than $6 \mathrm{~h}$, and the attention was put on the increase of acid groups on the surface of the carbon because they were used as anchors for proteins or contamination, depending on the application [26]. In the electrochemical capacitor, oxygen-containing surface groups have an important influence on the wettability of the carbon material and capacitance by the appearance of an additional redox reaction [11]. However, the hydroxyl groups like the quinon-hydroquinon couple are more desirable in energy storage application due to electrochemical reactions, which increase the specific capacitance of the material. Moreover, the processes described in the literature were proceeded under strong acid conditions (solution of 1-2 $\mathrm{M} \mathrm{H}_{2} \mathrm{SO}_{4}$ ) $[24,26]$. In these studies, a decrease of $\mathrm{pH}$ was not performed because it was expected that this will lead to stronger oxidation of the carbon surface. Harsh conditions of the modification process may lead to a collapse of the pore structure, and in consequence, a decrease of the surface area, which are unfavourable in the context of electrochemical capacitor application.

The aim of this work was to increase the capacity of the electrochemical capacitor, operating in various aqueous electrolytes, by modification of the commercial carbon material by a simple chemical method, at room temperature $\left(25^{\circ} \mathrm{C}\right)$. The ammonium persulfate solution was used as a modifier. The persulfate ions are characterised by a high redox potential $E^{\ominus}=2.01 \mathrm{~V}$ similar to ozone $\left(E^{\ominus}=2.07 \mathrm{~V}\right)$, which indicates great oxidation reactivity [27, 28]. Kinetics of the modification process and the changes of the carbon surface were also investigated. To the best of our knowledge, the activated carbon modified by ammonium persulfate was not previously applied in supercapacitors.

\section{Methodology}

\section{The modification process}

The $50 \mathrm{ml}$ of $2 \mathrm{M}$ ammonium persulfate (Sigma-Aldrich) was prepared shortly before the addition of $1 \mathrm{~g}$ commercial activated carbon (Norit ${ }^{\circledR}$ GSX). The solution was stirred during the entire process. The modifications were performed for 30 , 60, and $120 \mathrm{~min}$, and the samples were named S1, S2 and S3, respectively. The pristine material was signed as S0. After modification, the activated carbons were washed by distilled water.

\section{Kinetics measurements}

The methodology of Liang et al. [27] was used. The $1 \mathrm{ml}$ of solution was taken for analysis after a given period of time during $2 \mathrm{~h}$ of the process carried out without and with the carbon material. The spectrophotometer Rayleigh UV-Vis was used in the analysis. The measurements were conducted in the glass cuvettes at the $352 \mathrm{~nm}$.

\section{Material analysis}

The obtained material and the pristine one were analysed by thermal gravimetric analysis (TGA), Raman spectroscopy, Fourier transform infrared spectroscopy (FTIR), elemental analysis and by specific surface analysis (BET).

Thermal gravimetric analysis was carried for the pristine and the modified activated carbon in an argon atmosphere. The mass loss of the material was analysed in the temperature range from 40 to $900^{\circ} \mathrm{C}$. In a typical measurement sample, the activated carbon was examined with heating ramp $5{ }^{\circ} \mathrm{C} \mathrm{min}^{-1}$ using Netzsch STA 409 (NETZSCH-Gerätebau GmbH).

Raman spectroscopy measurements were performed by Via Renishaw micro-Raman system with an argon laser, emitting $514.5 \mathrm{~nm}$ wavelength.

FTIR spectra were recorded on $\mathrm{KBr}$ disc by using the FTIR Bruker Equinox 55 with frequency resolution $\pm 1 \mathrm{~cm}^{-1}$.

The composition of samples was measured using the elemental analysis by means of VARIO MICRO CUBE (Elementar Analysensysteme $\mathrm{GmbH}$ ). 
The surface area and changes in the porous texture were analysed by the nitrogen adsorption method at $77 \mathrm{~K}$ (Micromeritics ASAP 2010 volumetric adsorption system).

\section{Electrochemical measurement}

The activated carbon samples were used to prepare the electrodes in the form of pellets with the average mass of $10 \mathrm{mg}$ and with the geometric surface area of $0.79 \mathrm{~cm}^{2}$. Each electrode was composed of $85 \mathrm{wt} \%$ activated carbon, $5 \mathrm{wt} . \%$ acetylene carbon black (Super C65, Imerys) and $10 \mathrm{wt} \%$ of binder polytetrafluoroethylene (Sigma-Aldrich). The electrochemical studies were proceeded in the two and three electrodes cells (Swagelok® type) in three electrolytes: $1 \mathrm{M} \mathrm{H}_{2} \mathrm{SO}_{4}, 6 \mathrm{M}$ $\mathrm{KOH}$, and $1 \mathrm{M} \mathrm{Na}_{2} \mathrm{SO}_{4}$. For three-electrode measurements in $6 \mathrm{M} \mathrm{KOH}$, mercury/mercury oxide reference electrode $(\mathrm{Hg} / \mathrm{HgO}$ in $6 \mathrm{M} \mathrm{KOH})$ with potential $+0.098 \mathrm{~V}$ versus a normal hydrogen electrode (NHE) was used. For threeelectrode measurements in $1 \mathrm{M} \mathrm{H}_{2} \mathrm{SO}_{4}$ and in $1 \mathrm{M} \mathrm{Na}_{2} \mathrm{SO}_{4}$, mercury/mercury sulphate reference electrode $\left(\mathrm{Hg} / \mathrm{Hg}_{2} \mathrm{SO}_{4}\right.$ in $1 \mathrm{M} \mathrm{H}_{2} \mathrm{SO}_{4}$ ) with potential $+0.673 \mathrm{~V}$ versus NHE was used. All potential values are presented versus NHE.

The cyclic voltammetry $\left(1-100 \mathrm{mV} \mathrm{s}^{-1}\right)$, galvanostatic charge-discharge (100-5000 $\left.\mathrm{mA} \mathrm{g}^{-1}\right)$ and electrochemical impedance spectroscopy $(1 \mathrm{mHz}-100 \mathrm{kHz})$ were used to evaluate the electrochemical performance. The cyclability of the capacitors was determined by 5000 galvanostatic charge/ discharge cycles at current density $2 \mathrm{~A} \mathrm{~g}^{-1}$. Self-discharge of supercapacitors was investigated by leaving them in open circuit conditions during $20 \mathrm{~h}$.

\section{Results and discussion}

\section{Kinetics measurements}

The amount of persulfate ions that reacted with the carbon material was calculated using the difference between the concentrations of ions during the process carried out with and without the activated carbon, the results of which are presented in Fig. 1. The highest oxidation rate was observed during the first $60 \mathrm{~min}$ of modification. Longer oxidation showed only a slight increase in the amount of reacted ions.

\section{Thermal gravimetric analysis}

The amount and types of surface groups can be estimated upon TGA (Fig. 2a) and differential counterpart curves DTG (differential thermal analysis - Fig. 2b). In oxygen-free atmosphere, groups with oxygen and water present on the surface of the activated carbon should decompose with evolution of $\mathrm{CO}_{2}$, $\mathrm{CO}$ and $\mathrm{H}_{2} \mathrm{O}$ [29-31]. Water, which is adsorbed on the surface of the material, should evaporate at the beginning

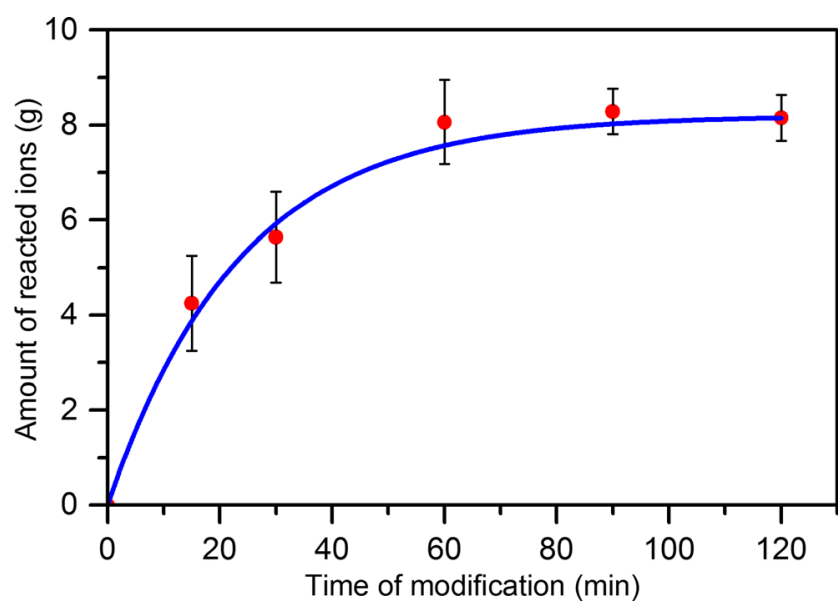

Fig. 1 Amount of reacted persulfate ions with activated carbon depending on the modification time

of the measurement (between 40 and $200{ }^{\circ} \mathrm{C}$ ). Carboxylic groups and other analogical groups decompose to carbon dioxide and water between 200 and $400{ }^{\circ} \mathrm{C}$. Carbon oxide, which is correlated with esters, phenols, carbonyls and quinones, decomposes at higher temperatures, between 400 and $900{ }^{\circ} \mathrm{C}$.
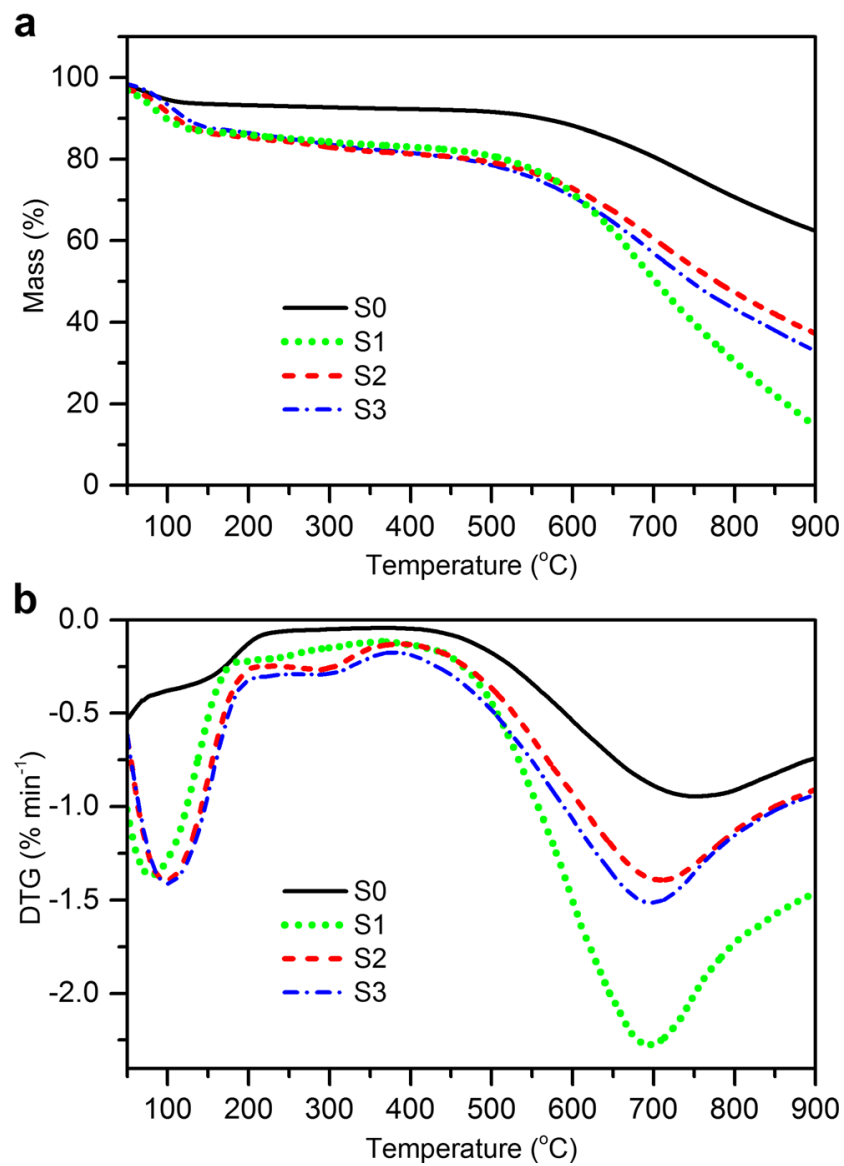

Fig. 2 Thermal gravimetric measurements. a Mass loss. b DTG curves of the examined materials 
The pristine sample exhibited almost no adsorbed water. Differently performed modified activated carbons, in all cases, exhibited a much larger amount of bounded water than S0, which is visible as a sharp peak on the DTG curve around $100{ }^{\circ} \mathrm{C}$. This has contributed to a higher hydrophilicity of the oxidised activated carbon and better wettability.

The amount of $\mathrm{C}-\mathrm{O}$ groups strongly increases after the first $30 \mathrm{~min}$ of modification, which is proof of a fast reaction between persulfate ions and active centres of the carbon surface. After formation of $\mathrm{C}-\mathrm{O}$ groups, further oxidation (up to $60 \mathrm{~min}$ ) is connected with oxidation of carbonyl and hydroxyl groups to carboxylic and other related functional groups. This can be observed from an increase of the peak around $300{ }^{\circ} \mathrm{C}$ (connected with $\mathrm{CO}_{2}$ evolution) and a decrease of the peak around $700{ }^{\circ} \mathrm{C}$ (connected with $\mathrm{CO}$ evolution). Longer oxidation time, up to $120 \mathrm{~min}$, results in a larger amount of $\mathrm{CO}_{2}$ and C-O-related groups, probably due to long oxidation time; persulfate radicals not only reacted with highly active centres of carbon but also with other less active parts of the surface.

\section{Raman spectroscopy}

Changes in D-band to G-band intensity ratio, presented in Fig. 3, indicate higher disorientation in the structure of activated

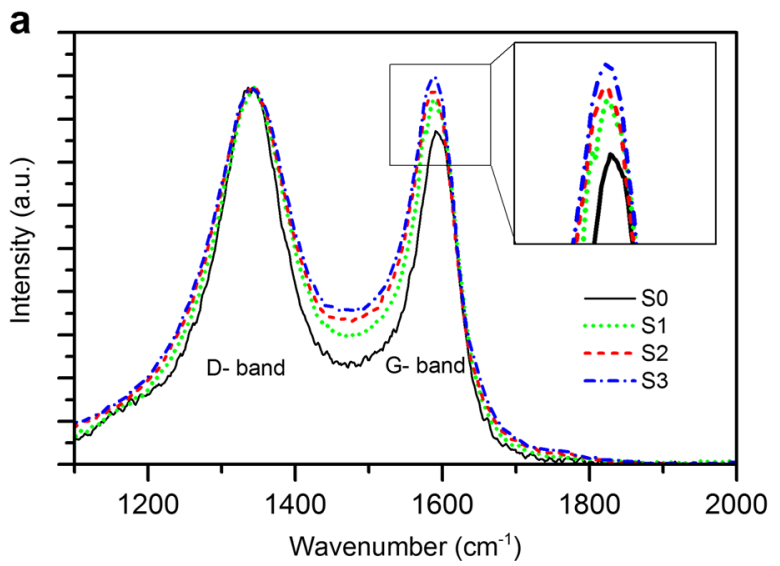

b

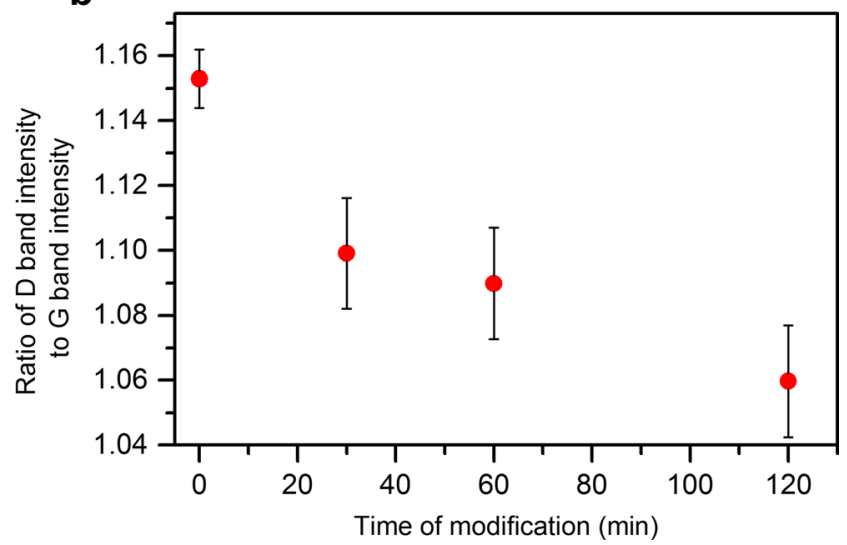

Fig. 3 Raman spectroscopy measurements. a Raman spectra. b D band intensity to $\mathrm{G}$ band intensity in comparison to the modification time carbon with an increase of the modification time [32]. Additionally, the ratio of D-band to G-band intensity (Fig. 3b) is in good correlation with the amount of persulfate ions that reacted with the sample, presented earlier. Fast-reacting radicals disorganise the carbon structure mostly during the first $60 \mathrm{~min}$ of the modification. Further oxidation leads only to moderate changes in the activated carbon surface.

\section{FTIR spectroscopy}

The FTIR spectroscopy measurement (Fig. 4) was used to determine surface functionality of the unmodified and modified carbon material. The wide band of about $3400-3500 \mathrm{~cm}^{-1}$ is connected with $-\mathrm{OH}$ stretching vibration. The peak of about $1260-1180 \mathrm{~cm}^{-1}$ is characteristic for vibration of $\mathrm{C}-\mathrm{O}$ groups connected into aromatic ring. The band at $1097 \mathrm{~cm}^{-1}$ is assigned to stretching vibration of $\mathrm{C}-\mathrm{O}$ bond. The band in 1720 and $1650 \mathrm{~cm}^{-1}$ region is assigned to the $\mathrm{C}=\mathrm{O}$, which appear in carbonyl, carboxylic acid and the quinone groups.

Results shows that, with increasing oxidation time, part of the hydroxyl groups is oxidised into carbonyl and carboxyl groups (decrease in $\mathrm{O}-\mathrm{H}$ band intensity and increase of $\mathrm{C}=\mathrm{O}$ band intensity). Also, a simultaneous decrease of $\mathrm{O}-\mathrm{H}$ band intensity and increase of $\mathrm{C}-\mathrm{O}$ band intensity suggest that, during long modification, further oxidation took place and intermediate groups appeared, such as ether, ester, lactone or pyrone-like groups [25]. The presented results are in good agreement with TGA analysis.

\section{Elemental and BET analysis}

The percentage amount of carbon, hydrogen, nitrogen, sulphur and oxygen (the last calculated as a difference) and BET surface measurements of the examined samples are presented in Table 1. Similar to other results, the amount of oxygen atoms in the samples increases with an increase of the reaction time between the persulfate ions and the activated

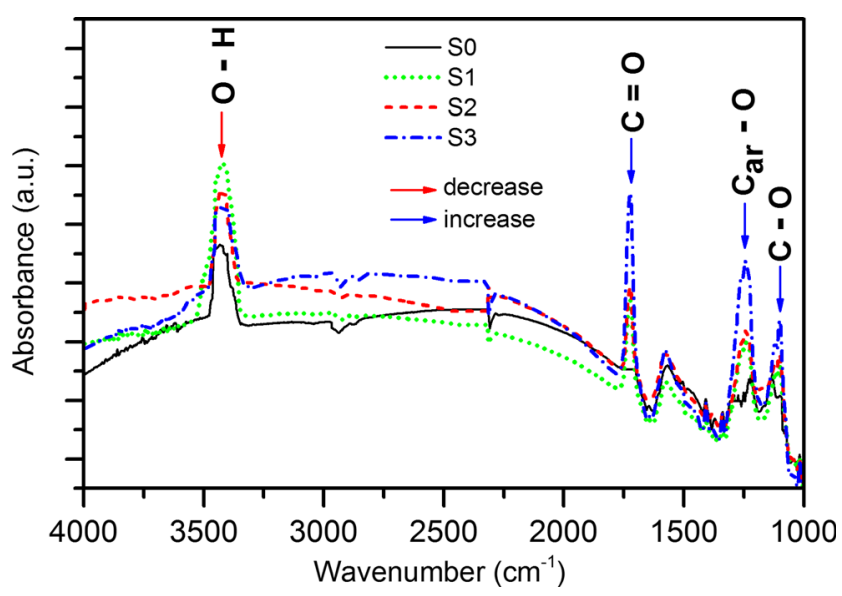

Fig. 4 FTIR spectra. 
Table 1 Elemental and BET analysis results

\begin{tabular}{lllllll}
\hline Sample & C (wt.\%) & H (wt.\%) & N (wt.\%) & S (wt.\%) & O (wt.\%) by diff. & BET surface area $\left(\mathrm{m}^{2} \mathrm{~g}^{-1}\right)$ \\
\hline S0 & 85.78 & 0.45 & 0.16 & 0.18 & 13.43 & 796 \\
S1 & 77.02 & 0.87 & 0.40 & 0.64 & 21.07 & 713 \\
S2 & 74.68 & 1.00 & 0.42 & 0.45 & 23.45 & 718 \\
S3 & 73.89 & 0.95 & 0.39 & 0.51 & 24.26 & 713 \\
\hline
\end{tabular}

carbon. The highest rise of oxygen content is observed after 30 min of modification.

The surface area and changes in the porous texture were analysed by the nitrogen adsorption method at $77 \mathrm{~K}$, as it is shown in Fig. 5a, b. In all cases, the BET surface area decreased. Unmodified activated carbon has a better developed specific surface area than the modified one. It can be concluded that the walls of pores are destroyed after being modified with ammonium persulfate. Moreover, it can be connected with higher disorientation of the carbon structure or with blockage of pores with surface groups. Figure 5a shows clearly that all isotherms are characteristic of microporous materials with a small number of mesopores, which are responsible for transporting ions into micropores. The pore
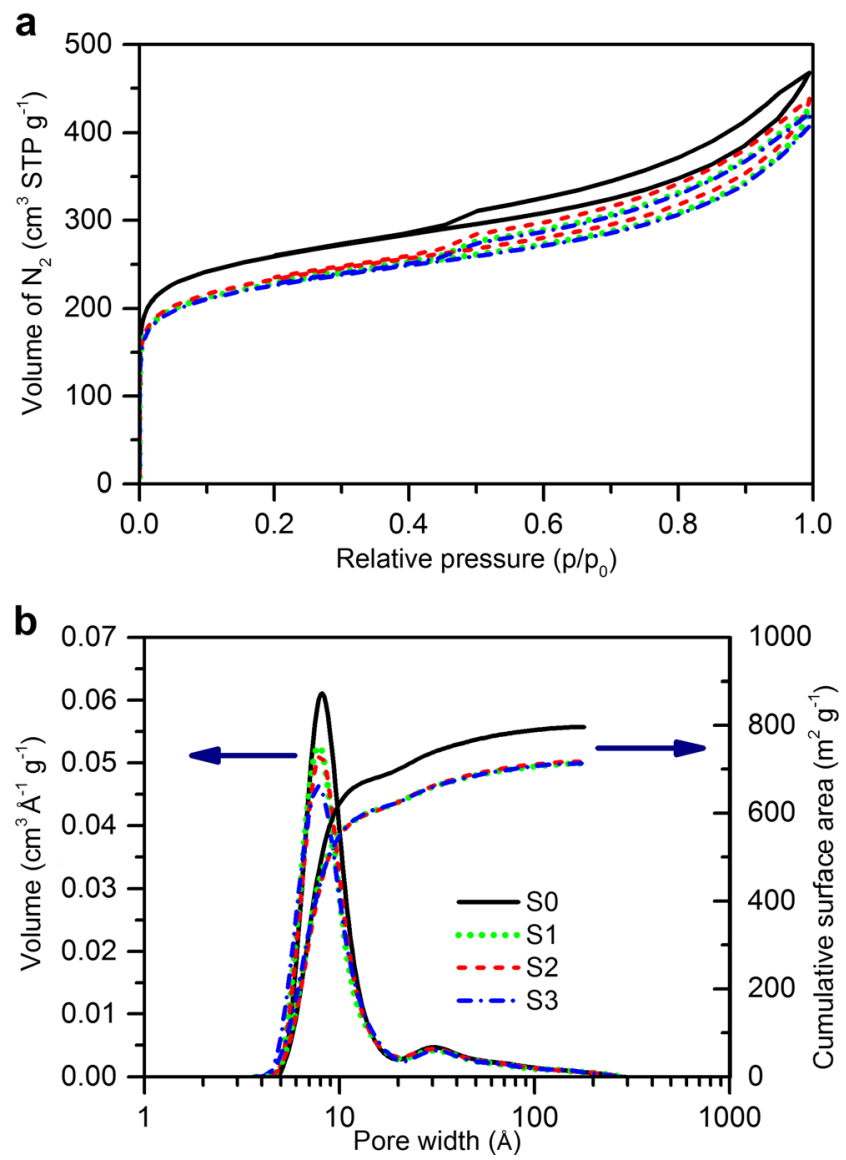

Fig. 5 a Nitrogen adsorption/desorption isotherms (77 K). b Pore size distribution of carbon materials size distribution of carbons (PSD, calculated by NLDFT method with a heterogeneous surface model using SAIEUS Program, ver. 1.02, by J. Jagiello) [33] confirmed the unimodal PSD profile with the highest contribution of micropores, as shown in Fig. 5b. Additionally, the volume of micropores decreases as modification time grows.

\section{Electrochemical measurements}

\section{Characterisation in $1 \mathrm{M} \mathrm{H}_{2} \mathrm{SO}_{4}$}

A comprehensive electrochemical characterisation of the modified materials in comparison to the unmodified one is presented in Table 2. Cyclic voltammetry curves in two electrode cells at $10 \mathrm{mV} \mathrm{s}^{-1}$ (Fig. 6a) indicate a similar increase of the capacitance in the case of all the oxidised activated carbons. It implies that even a very short time of the modification using ammonium persulfate can strongly increase the specific capacitance of the activated carbon. This is probably connected with a high increase of hydrophilicity of the activated carbon and, additionally, the appearance of electroactive surface groups, which react with protons from the electrolyte.

Three electrode measurements allowed to designate the behaviour of separate electrodes. Figure $6 \mathrm{~d}-\mathrm{f}$ shows cyclic voltammetry measurements of three electrode cells at $5 \mathrm{mV} \mathrm{s}^{-1}$ of unmodified activated carbon and after the chemical treatment. Reversible peak on the negative electrode at potential around $0.6 \mathrm{~V}$ versus NHE, which occurs in all modified materials, indicates the appearance of the pseudocapacitance effect, which by fast faradic reactions generates additional capacitance. This enhancement of

Table 2 Electrochemical performance of supercapacitors with electrodes made from $\mathrm{S} 0, \mathrm{~S} 1, \mathrm{~S} 2$ and $\mathrm{S} 3$ activated carbon samples in $1 \mathrm{M} \mathrm{H}_{2} \mathrm{SO}_{4}$ as the electrolyte

\begin{tabular}{lllll}
\hline Method & $\mathrm{S} 0\left(\mathrm{~F} \mathrm{~g}^{-1}\right)$ & $\mathrm{S} 1\left(\mathrm{~F} \mathrm{~g}^{-1}\right)$ & $\mathrm{S} 2\left(\mathrm{~F} \mathrm{~g}^{-1}\right)$ & $\mathrm{S} 3\left(\mathrm{~F} \mathrm{~g}^{-1}\right)$ \\
\hline $1 \mathrm{mV} \mathrm{s}^{-1}$ & 101 & 126 & 127 & 130 \\
$10 \mathrm{mV} \mathrm{s}^{-1}$ & 92 & 109 & 110 & 114 \\
$100 \mathrm{mV} \mathrm{s}^{-1}$ & 77 & 79 & 91 & 91 \\
$100 \mathrm{~mA} \mathrm{~g}^{-1}$ & 98 & 122 & 124 & 127 \\
$1000 \mathrm{~mA} \mathrm{~g}^{-1}$ & 89 & 105 & 108 & 111 \\
$2000 \mathrm{~mA} \mathrm{~g}^{-1}$ & 85 & 97 & 103 & 106 \\
\hline
\end{tabular}


Fig. 6 Electrochemical performance of the examined materials in $1 \mathrm{M} \mathrm{H}_{2} \mathrm{SO}_{4}$. a Cyclic voltammetry of two electrode cells at $10 \mathrm{mV} \mathrm{s}^{-1}$. b

Electrochemical impedance spectroscopy of two electrode cells. c Cyclability at $2 \mathrm{~A} \mathrm{~g}^{-1}$. d-f Cyclic voltammetry of three electrode cells at $5 \mathrm{mV} \mathrm{s}^{-1}$ for $\mathrm{S} 1$, $\mathrm{S} 2$ and $\mathrm{S} 3$ as electrode material in comparison to $\mathrm{S} 0$. a

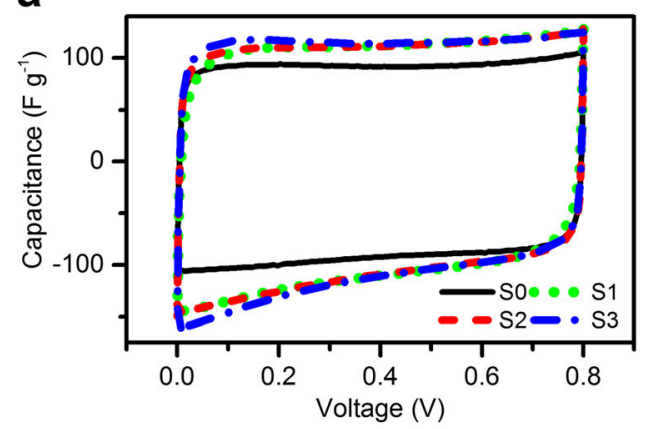

b

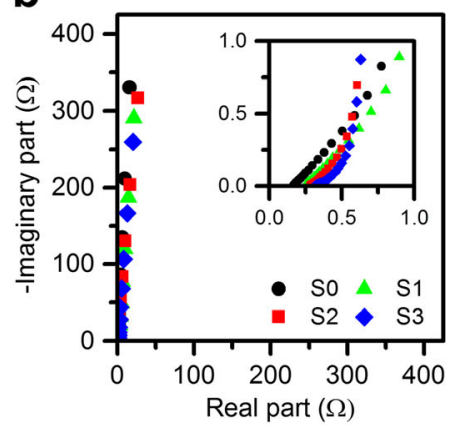

C

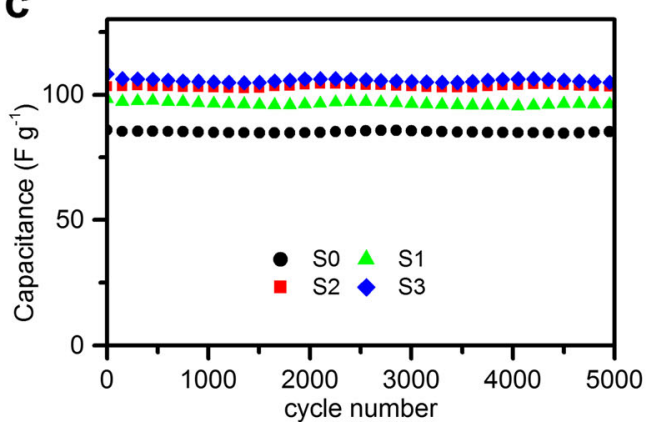

d

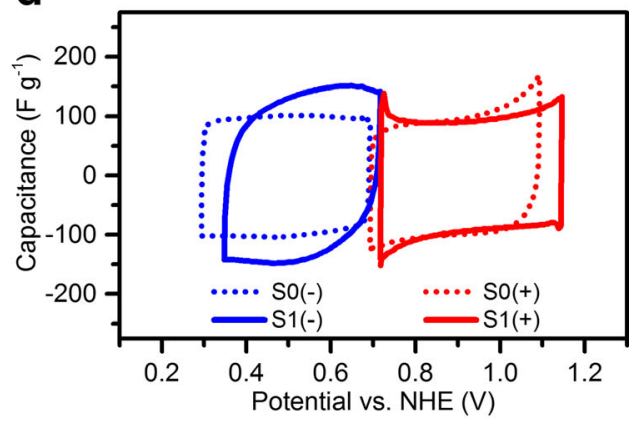

e

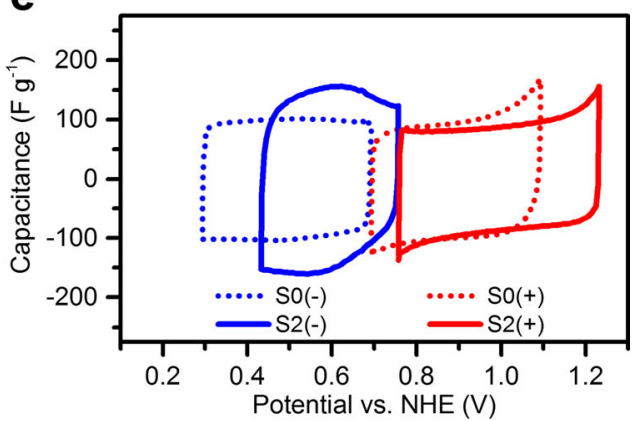

f

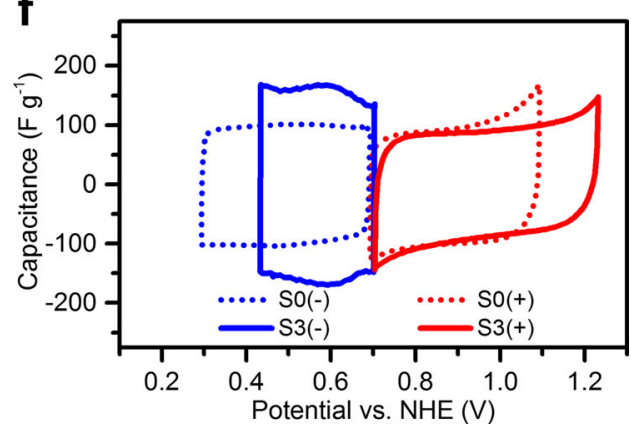

capacitance is connected with the quinone-hydroquinone redox pair, and in acidic electrolyte, it is connected with the reaction given in Fig. 7 [34].

Niquist's plots of electrochemical impedance spectroscopy measurements presented in Fig. 6b showed that the modification of the activated carbon by ammonium persulfate leads to higher resistivity of the material. This is directly connected with the appearance of heteroatoms in the material structure. A higher amount of oxygen decreased the conductivity of the electrode material.
The stability of electrochemical capacitors, which utilised an unmodified and oxidised electrode material, was investigated by 5000 galvanostatic charge/discharge cycles at current density $2 \mathrm{~A} \mathrm{~g}^{-1}$ (Fig. 6c). Capacitance of supercapacitors did not significantly change, and after this long cycling, it was the same as the initial value for those materials. Self-discharge of electrochemical capacitors with modified activated carbon in acidic medium increased after a period of $20 \mathrm{~h}$ by 13,18 and $45 \mathrm{mV}$ for S1, S2 and S3 in comparison to S0 (Table 3).
Fig. 7 Hydroquinone-quinone redox pair.

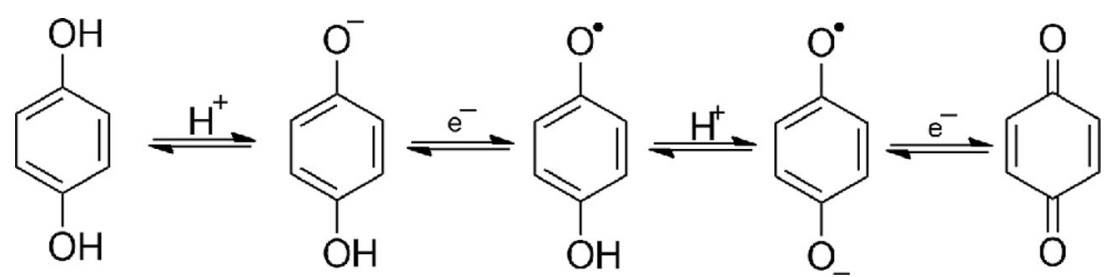


Table 3 The self-discharge of supercapacitor after $20 \mathrm{~h}$

\begin{tabular}{llll}
\hline Sample & $1 \mathrm{M} \mathrm{H}_{2} \mathrm{SO}_{4}(\mathrm{~V})$ & $6 \mathrm{M} \mathrm{KOH}(\mathrm{V})$ & $1 \mathrm{M} \mathrm{Na}_{2} \mathrm{SO}_{4}(\mathrm{~V})$ \\
\hline S0 & 0.486 & 0.412 & 0.509 \\
S1 & 0.473 & 0.308 & 0.489 \\
S2 & 0.468 & 0.298 & 0.468 \\
S3 & 0.441 & 0.278 & 0.452 \\
\hline
\end{tabular}

\section{Characterisation in $6 \mathrm{M} \mathrm{KOH}$}

The electrochemical performance, tested with cyclic voltammetry and galvanostatic charge/discharge of supercapacitors working in alkaline electrolyte, is presented in Table 4. Differently than in the case of electrochemical capacitors working in acidic electrolyte, the increase of capacitance is more dependent on the time of the modification. Cyclic voltammetry measurements of two electrode cells at $10 \mathrm{mV} \mathrm{s}^{-1}$ are presented in Fig. 8a. Similar to acidic electrolyte, an increase of the hydrophilicity and the appearance of redox reactions allowed to obtain higher values of capacitance, even if the BET surface of the modified activated carbon decreased.

Three electrode cyclic voltammetry measurements at $5 \mathrm{mV} \mathrm{s}^{-1}$ revealed a very broad and reversible peak, which is present in the entire potential of the negative electrodes and slightly on the positive electrodes (Fig. 8d-f). In highly alkaline medium oxygen-containing groups, which are of a pyrone-like nature, $\mathrm{C}-\mathrm{O}$ and $\mathrm{O}-\mathrm{C}=\mathrm{O}$ are active [35]. Prolonged modification of the activated carbon results in the appearance of higher oxidised functional groups. Changes in the resonance structure of the pyrone-like groups, and the appearance of the positive and negative charge on the oxygen atoms, lead to an improvement of the interaction between ions from the electrolyte with the surface of the activated carbon. This can be presented by changes in resonance structure given in Fig. 9 [36].

Electrochemical impedance spectroscopy in two electrode systems (Fig. 8b) showed that, differently than in the case of $1 \mathrm{M} \mathrm{H}_{2} \mathrm{SO}_{4}$, electrochemical capacitors, which operate in an alkaline electrolyte, do not increase their resistivity with an

Table 4 Electrochemical performance of supercapacitors with electrodes made from S0, S1, S2 and S3 activated carbon samples in $6 \mathrm{M} \mathrm{KOH}$ as the electrolyte

\begin{tabular}{lllll}
\hline Method & $\mathrm{S} 0\left(\mathrm{~F} \mathrm{~g}^{-1}\right)$ & $\mathrm{S} 1\left(\mathrm{~F} \mathrm{~g}^{-1}\right)$ & $\mathrm{S} 2\left(\mathrm{~F} \mathrm{~g}^{-1}\right)$ & $\mathrm{S} 3\left(\mathrm{~F} \mathrm{~g}^{-1}\right)$ \\
\hline $1 \mathrm{mV} \mathrm{s}^{-1}$ & 94 & 118 & 124 & 125 \\
$10 \mathrm{mV} \mathrm{s}^{-1}$ & 82 & 103 & 111 & 113 \\
$100 \mathrm{mV} \mathrm{s}^{-1}$ & 42 & 62 & 79 & 83 \\
$100 \mathrm{~mA} \mathrm{~g}^{-1}$ & 91 & 115 & 119 & 120 \\
$1000 \mathrm{~mA} \mathrm{~g}^{-1}$ & 78 & 97 & 108 & 110 \\
$2000 \mathrm{~mA} \mathrm{~g}^{-1}$ & 69 & 86 & 101 & 104 \\
\hline
\end{tabular}

increase of the oxygen content in the electrode material. The resistivity of the charge transfer, which is visible at the end of the semicircle, decreases from the pristine activated carbon until $60 \mathrm{~min}$ of the modification and again increases after $120 \mathrm{~min}$ of the modification. This decrease of charge transfer resistance is probably connected with the appearance of charge on the oxygen atoms during operation of this material in an electrochemical capacitor, as it was mentioned earlier.

Galvanostatic cycling measurements showed only a slight decrease of the capacitance during 5000 cycles (Fig. 8c), which indicate high reversibility of redox reactions that takes place on the surface of the modified material. In the case of alkaline electrolyte, voltages after self-discharge measurements were 104, 114 and $134 \mathrm{mV}$ lower in S1, S2 and S3 electrochemical capacitors, respectively, in comparison to unmodified material (Table 3).

\section{Characterisation in $1 \mathrm{M} \mathrm{Na}_{2} \mathrm{SO}_{4}$}

Capacitance values of the examined electrochemical capacitors in $1 \mathrm{M}$ sodium sulphate (VI) at different conditions are shown in Table 5. Voltammograms of two electrode measurements of S0, S1, S2 and S3 recorded at $10 \mathrm{mV} \mathrm{s}^{-1}$ in neutral electrolyte are presented in Fig. 10a. The increase of capacitance with increasing time of the modification has more linear behaviour than in alkaline or acidic electrolyte.

Cyclic voltammetry measurements in three electrode cells, presented in Fig. 10d-f, show no peaks, which is different than the other examined electrolytes. An increase of the specific capacitance of both electrodes can be seen. Some researchers show no influence of oxygen groups on the capacitance of the material in neutral electrolyte, indicating a lack of faradic reactions that can occur on the electrode material [11]. In the conducted measurements, the increase of the capacitance of both positive and negative electrodes can be connected with the overall level of oxygen content in the material. That caused better wettability of the electrode surface and a decrease of the charge transfer resistance (Fig. 10b). Similar results were reported by Bichat et al. [35].

Cyclic galvanostatic charge/discharge measurements at $2 \mathrm{~A} \mathrm{~g}^{-1}$ (Fig. 10c) show no changes in the specific capacitance of the electrochemical capacitor during 5000 consecutive cycles. Self-discharge measured in neutral medium was higher than in the case of unmodified one by 20,41 and $57 \mathrm{mV}$ for S1, S2 and S3, respectively (Table 3).

\section{Conclusions}

In summary, the commercial material modified by the use of a persulfate solution with various times was physicochemical and electrochemical when characterised and compared with the unmodified one. The modification influences various 
Fig. 8 Electrochemical performance of examined materials in $6 \mathrm{M} \mathrm{KOH}$. a Cyclic voltammetry of two electrode cells at $10 \mathrm{mV} \mathrm{s}^{-1} \cdot \mathbf{b}$

Electrochemical impedance spectroscopy of two electrode cells. c Cyclability at $2 \mathrm{~A} \mathrm{~g}^{-1}$. d-f Cyclic voltammetry of three electrode cells at $5 \mathrm{mV} \mathrm{s}^{-1}$ for $\mathrm{S} 1$, $\mathrm{S} 2$ and $\mathrm{S} 3$ as the electrode material in comparison to $\mathrm{S} 0$ a

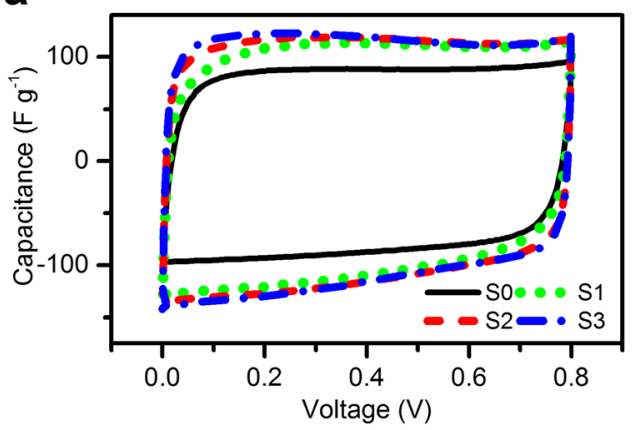

b

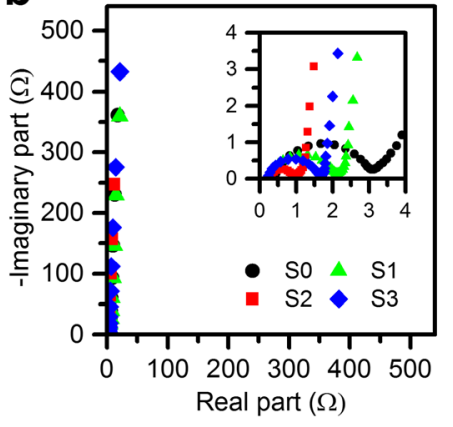

C

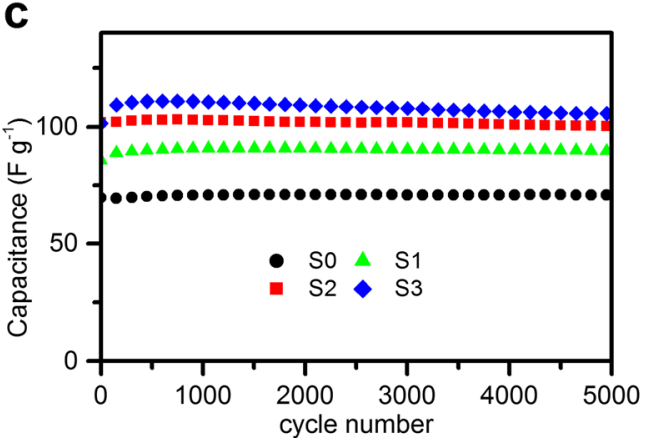

d

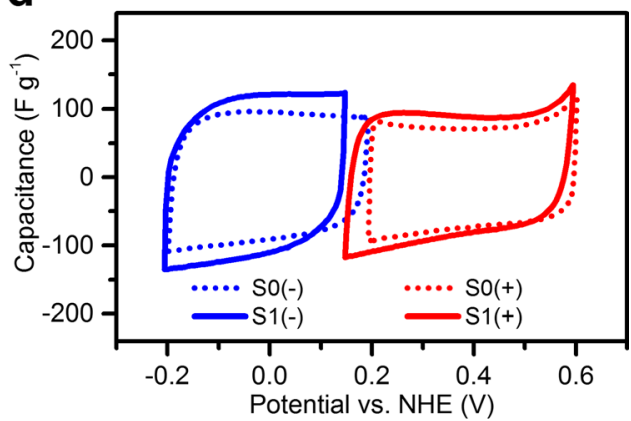

e

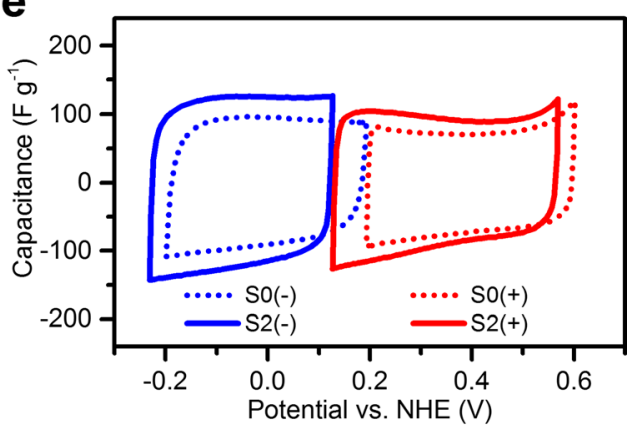

f

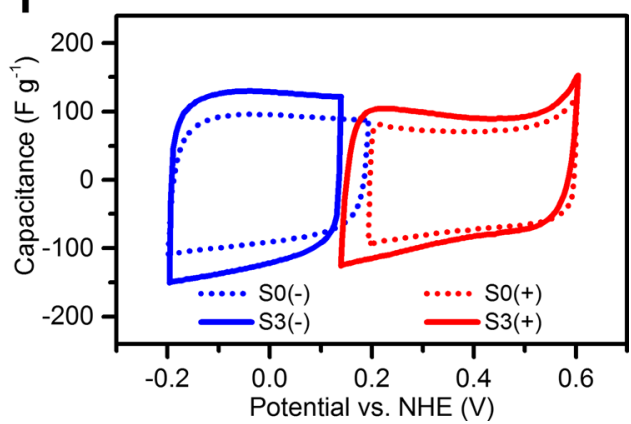

properties of the material, mainly the oxygen content in it. However, the increased number of oxygen functional groups, such as hydroxyl, carbonyl and carboxyl, results in the slight decrease of the surface area. The short time modification and application of mild conditions result mainly in an increase of the hydroxyl and carbonyl groups - the most suitable ones in energy storage devices. These changes of physicochemical properties had the highest effect on the electrochemical parameters of the carbon electrode system operating in $1 \mathrm{M}$ $\mathrm{H}_{2} \mathrm{SO}_{4}$. A significant increase of capacitance, by $25 \%$, after only $30 \mathrm{~min}$ of modification, was observed, and later, the capacitance grew only by 27 and $28 \%$ after 60 and $120 \mathrm{~min}$, respectively. The capacitance of the capacitor operated in $6 \mathrm{M}$ $\mathrm{KOH}$ was enhanced up to $60 \mathrm{~min}$ of modification by $32 \%$; further oxidation increased the specific capacitance only to $33 \%$ in comparison to the unmodified material. Moreover, the dependence between the time of modification and the capacitance of the electrode system with $1 \mathrm{M} \mathrm{Na}_{2} \mathrm{SO}_{4}$ electrolyte was noticed and resulted in an increase of the capacitance by 27, 48 and $57 \%$ after 30,60 and 120 min of modification, respectively. The conducted kinetic studies showed that, during longer oxidation in given conditions, the amount of persulfate ions that are able to react with the material is limited. Oxidation longer than 60 min results in an insufficient increase of the specific capacitance in comparison to the time of modification. In the conducted study, similar masses of positive and negative electrodes were used. The results indicated that in the case of electrochemical capacitors working in

Fig. 9 Resonance structures of the pyrone group

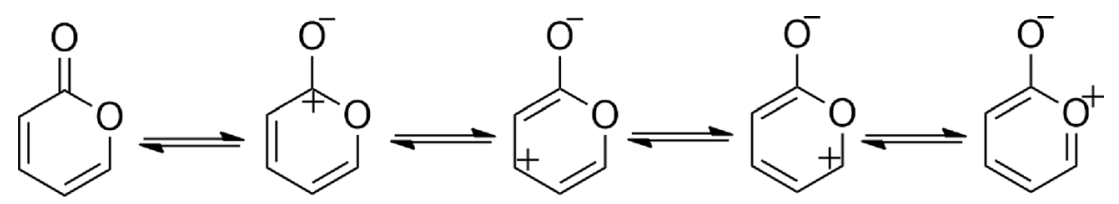


Table 5 Electrochemical performance of supercapacitors with electrodes made from S0, S1, S2 and S3 activated carbon samples in $1 \mathrm{M} \mathrm{Na}_{2} \mathrm{SO}_{4}$ as the electrolyte

\begin{tabular}{lllll}
\hline Method & $\mathrm{S} 0\left(\mathrm{~F} \mathrm{~g}^{-1}\right)$ & $\mathrm{S} 1\left(\mathrm{~F} \mathrm{~g}^{-1}\right)$ & $\mathrm{S} 2\left(\mathrm{~F} \mathrm{~g}^{-1}\right)$ & $\mathrm{S} 3\left(\mathrm{~F} \mathrm{~g}^{-1}\right)$ \\
\hline $1 \mathrm{mV} \mathrm{s}^{-1}$ & 60 & 76 & 89 & 94 \\
$10 \mathrm{mV} \mathrm{s}^{-1}$ & 50 & 61 & 68 & 74 \\
$100 \mathrm{mV} \mathrm{s}^{-1}$ & 15 & 33 & 44 & 52 \\
$100 \mathrm{~mA} \mathrm{~g}^{-1}$ & 58 & 69 & 82 & 88 \\
$1000 \mathrm{~mA} \mathrm{~g}^{-1}$ & 46 & 51 & 60 & 68 \\
$2000 \mathrm{~mA} \mathrm{~g}^{-1}$ & 35 & 42 & 53 & 62 \\
\hline
\end{tabular}

acidic electrolyte, the capacitance of negative electrode mainly increased. In the case of neutral and alkaline media, both positive and negative electrode capacitance increased similarly. The different mass ratio between the positive and negative electrodes in $1 \mathrm{M} \mathrm{H}_{2} \mathrm{SO}_{4}$ will most probably lead to even better performance of supercapacitor. Incorporation of oxygen heteroatoms in the structure of electrode material increased self-discharge of electrochemical capacitors. The lowest impact was observed for electrochemical capacitors working in acidic electrolyte. The highest differences between voltages after $20 \mathrm{~h}$ of open circuit voltage were observed for supercapacitors working in alkaline media. In all cases, longer modification resulted in worsening this parameter, which is another disadvantage of longer modification time than that crucial for obtaining higher capacitance values. In conclusion, the wet modification of the carbon material with a saturated ammonium persulfate solution at room temperature is a promising solution for increasing the capacity of carbon electrode systems with various aqueous electrolytes, but unfortunately, the introduction of oxygen heteroatoms in the carbon structure increases self-discharge, which may be a problem in practical use of such a material in electrochemical capacitors.

Acknowledgements The authors would like to acknowledge gratefully the financial support from the National Science Centre of Poland, grant No DEC-2013/10/E/ST5/00719. Imerys is acknowledged for providing the carbon black.
Fig. 10 Electrochemical measurements of examined materials in $1 \mathrm{M} \mathrm{Na}_{2} \mathrm{SO}_{4}$. a Cyclic voltammetry of two electrode cells at $10 \mathrm{mV} \mathrm{s}^{-1}$. b Electrochemical impedance spectroscopy of two electrode cell. c Cyclability at $2 \mathrm{~A} \mathrm{~g}^{-1}, \mathbf{d}-\mathbf{f}$ Cyclic voltammetry of three electrode cells at $5 \mathrm{mV} \mathrm{s}^{-1}$ for $\mathrm{S} 1$, $\mathrm{S} 2$ and $\mathrm{S} 3$ as the electrode material in comparison to S0. a

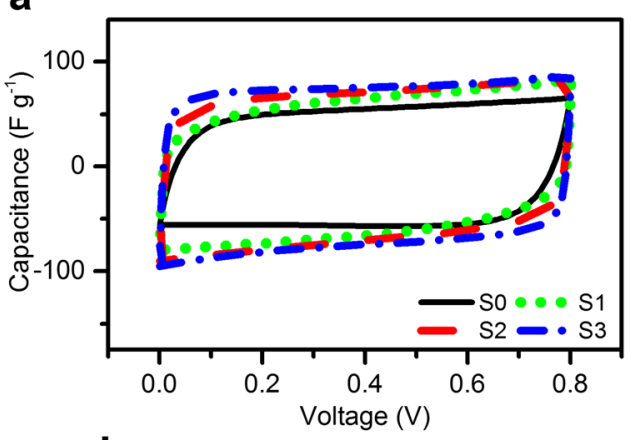

b

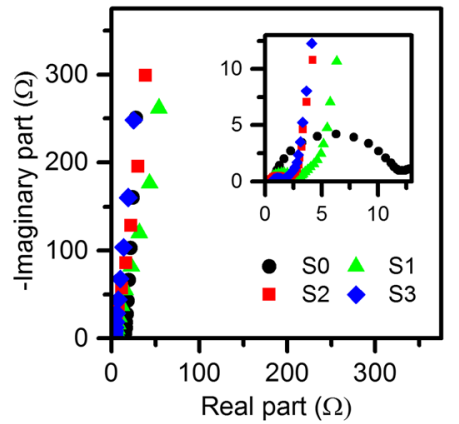

C

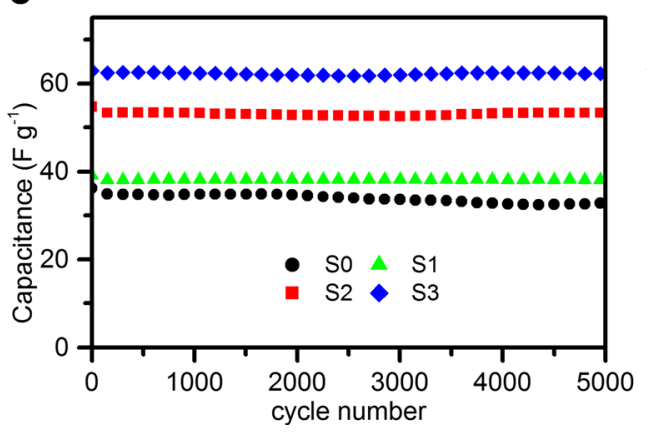

d

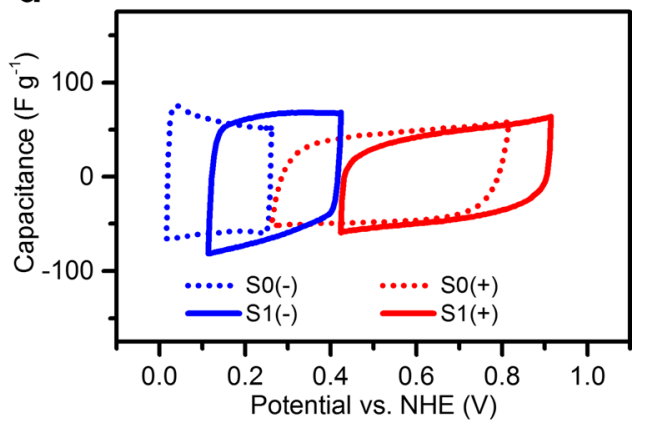

e

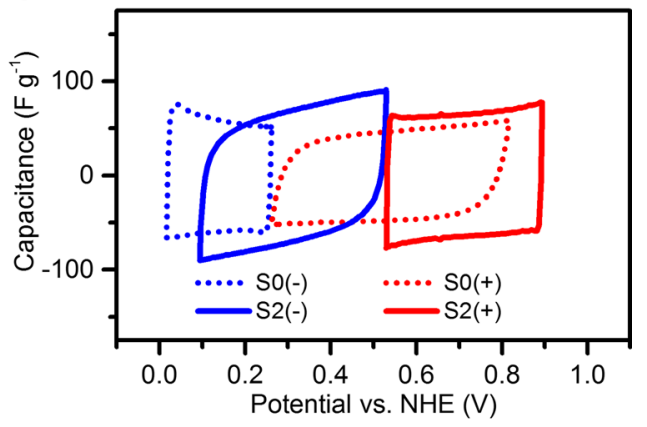

f

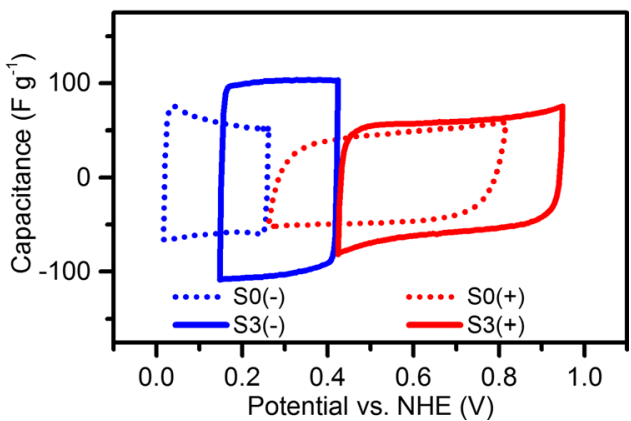


Open Access This article is distributed under the terms of the Creative Commons Attribution 4.0 International License (http:// creativecommons.org/licenses/by/4.0/), which permits unrestricted use, distribution, and reproduction in any medium, provided you give appropriate credit to the original author(s) and the source, provide a link to the Creative Commons license, and indicate if changes were made.

\section{References}

1. Wu T, Wang G, Dong Q, Qian B, Meng Y, Qiu J (2015) Asymmetric capacitive deionization utilizing nitric acid treated activated carbon fiber as the cathode. Electrochim Acta 176:426-433

2. Chen Y, Zhu Y, Wang Z, Li Y, Wang L, Ding L, Gao X, Ma Y, Guo Y (2011) Application studies of activated carbon derived from rice husks produced by chemical-thermal process - a review. Adv Colloid Interf Sci 163:39-52

3. Bhatnagar A, Hogland W, Marques M, Sillanpaa M (2013) An overview of the modification methods of activated carbon for its water treatment applications. Chem Eng J 219:499-511

4. Vivo-Vilches JF, Bailon-Garcia E, Perez-Cadenas AF, CarrascoMarin F, Maldonado-Hodar FJ (2013) Tailoring activated carbons for the development of specific adsorbents of gasoline vapors. $\mathrm{J}$ Hazard Mater 263:533-540

5. Tripathi PK, Liu M, Zhao Y, Ma X, Gan L, Noonan O, Yu C (2014) Enlargement of uniform micropores in hierarchically ordered micro-mesoporous carbon for high level decontamination of bisphenol A. J Mater Chem A 2:8534-8544

6. Zhao Y, Liu M, Gan L, Ma X, Zhu D, Xu Z, Chen L (2014) Ultramicroporous carbon nanoparticles for the high-performance electrical double-layer capacitor electrode. Energy and Fuels 28:1561-1568

7. Kierzek K, Frackowiak E, Lota G, Gryglewicz G, Machnikowski J (2004) Electrochemical capacitors based on highly porous carbons prepared by $\mathrm{KOH}$ activation. Electrochim Acta 49:515-523

8. Inagaki M, Konno H, Tanaike O (2010) Carbon materials for electrochemical capacitors. J Power Sources 195:7880-7903

9. Volfkovich YM, Bograchev DA, Rychagov AY (2015) Supercapacitors with carbon electrodes. Energy efficiency: modeling and experimental verification J Solid State Electrochem 19:2771-2779

10. Volfkovich YM, Bograchev DA, Mikhalin AA, Bagotsky VS (2014) Supercapacitor carbon electrodes with high capacitance. J Solid State Electrochem 18:1351-1363

11. Oh YJ, Yoo JJ, Kim YI, Yoon JK, Yoon HN, Kim JH, Bin Park S (2014) Oxygen functional groups and electrochemical capacitive behavior of incompletely reduced graphene oxides as a thin-film electrode of supercapacitor. Electrochim Acta 116:118-128

12. Li N, Ma X, Zha Q, Kim K, Chen Y, Song C (2011) Maximizing the number of oxygen-containing functional groups on activated carbon by using ammonium persulfate and improving the temperatureprogrammed desorption characterization of carbon surface chemistry. Carbon 49:5002-5013

13. Qu D (2002) Studies of the activated carbons used in double-layer supercapacitors. J Power Sources 109:403-411

14. Hsieh CT, Teng H (2002) Influence of oxygen treatment on electric double-layer capacitance of activated carbon fabrics. Carbon 40 : 667-674

15. Oda H, Yamashita A, Minoura S, Okamoto M, Morimoto T (2006) Modification of the oxygen-containing functional group on activated carbon fiber in electrodes of an electric double-layer capacitor. $\mathrm{J}$ Power Sources 158:1510-1516

16. Lu W, Liu M, Miao L, Zhu D, Wang X, Duan H, Wang Z, Li L, Xu Z, Gan L (2016) Nitrogen-containing ultramicroporous carbon nanospheres for high performance supercapacitor electrodes. Electrochim Acta 205:132-141
17. Jaramillo J, Alvarez PM, Gomez-Serrano V (2010) Oxidation of activated carbon by dry and wet methods surface chemistry and textural modifications. Fuel Process Technol 91:1768-1775

18. Ismanto AE, Wang S, Soetaredjo FE, Ismadji S (2010) Preparation of capacitor's electrode from cassava peel waste. Bioresour Technol 101:3534-3540

19. Lota K, Acznik I, Sierczynska A, Lota G (2016) The capacitance properties of activated carbon obtained from chitosan as the electrode material for electrochemical capacitors. Mater Lett 173:72-75

20. Lota G, Tyczkowski J, Makowski P, Balcerzak J, Lota K, Acznik I, Pęziak-Kowalska D, Kolanowski $Ł$ (2016) The modified activated carbon treated with a low-temperature iodine plasma used as electrode material for electrochemical capacitors. Mater Lett 175:96-100

21. Lota G, Krawczyk P, Lota K, Sierczyńska A, Kolanowski Ł, Baraniak M, Buchwald T (2016) The application of activated carbon modified by ozone treatment for energy storage. J Solid State Electrochem 20:2857-2864

22. Castro-Muniz A, Suarez-Garcia F, Martinez-Alonso A, Tascon JMD (2011) Activated carbon fibers with a high content of surface functional groups by phosphoric acid activation of PPTA. J Colloid Interface Sci 361:307-315

23. El-Hendawy ANA (2003) Influence of $\mathrm{HNO}_{3}$ oxidation on the structure and adsorptive properties of corncob-based activated carbon. Carbon 41:713-722

24. Goscianska J, Olejnik A, Nowak I, Marciniak M, Pietrzak R (2016) Stability analysis of functionalized mesoporous carbon materials in aqueous solution. Chem Eng J 290:209-219

25. Moreno-Castilla C, Carrasco-Marín F, Mueden A (1997) The creation of acid carbon surfaces by treatment with $\left(\mathrm{NH}_{4}\right)_{2} \mathrm{~S}_{2} \mathrm{O}_{8}$. Carbon 35:1619-1626

26. Vinu A, Hossian KZ, Srinivasu P, Miyahara M, Anandan S, Gokulakrishnan N, Mori T, Ariga K, Balasubramanian VV (2007) Carboxy-mesoporous carbon and its excellent adsorption capability for proteins. J Mater Chem 17:1819-1825

27. Liang C, Huang CF, Mohanty N, Kurakalva RM (2008) A rapid spectrophotometric determination of persulfate anion in ISCO. Chemosphere 73:1540-1543

28. Tröster I, Fryda M, Herrmann D, Schäfer L, Hänni W, Perret A, Blaschke M, Kraft A, Stadelmann M (2002) Electrochemical advanced oxidation process for water treatment using DiaChem ${ }^{\circledR}$ electrodes. Diam Relat Mater 11:640-645

29. Rodriguez-Reinoso F, Molina-Sabio M, Gonzalez MT (1997) Effect of oxygen surface groups on the immersion enthalpy of activated carbons in liquids of different polarity. Langmuir 13:2354-2358

30. Adib F, Bagreev A, Bandosz T (1999) Effect of surface characteristics of wood-based activated carbons on adsorption of hydrogen sulfide. J Colloid Interface Sci 214:407-415

31. Hemraj-Benny T, Bandosz TJ, Wong SS (2008) Effect of ozonolysis on the pore structure, surface chemistry, and bundling of singlewalled carbon nanotubes. J Colloid Interface Sci 317:375-382

32. Ferrari A, Robertson J (2000) Interpretation of Raman spectra of disordered and amorphous carbon. Phys Rev B 61:14095-14107

33. Jagiello J, Olivier JP (2013) 2D-NLDFT adsorption models for carbon slit-shaped pores with surface energetical heterogeneity and geometrical corrugation. Carbon 55:70-80

34. Frackowiak E, Meller M, Menzel J, Gastrol D, Fic K (2014) Redoxactive electrolyte for supercapacitor application. Faraday Discuss 172:179-198

35. Bichat MP, Raymundo-Pinero E, Beguin F (2010) High voltage supercapacitor built with seaweed carbons in neutral aqueous electrolyte. Carbon 48:4351-4361

36. Kerek F (2003) Macrocyclic compounds made from carbon suboxide units. 99:1-36 EP 000874851B1 